\title{
BELL
}

\section{ADVANCED ALGEBRA}

\section{by C. V. DURELL, M.A., and A. ROBSON, M.A.}

Vol. I, 4s. 9d. Vol. II, 6s. Vol. III, 7s. 6d. II and III together, I2s. 6d. Hints for Vols. II and III, 2s. 6d. net erch book.

Volume I (seventh edition) covers ordinary Higher Certificate requirements. Volumes II and III together cover the ground up to university entrance standard. " Throughout the text has been prepared with much skill, thoroughness and clarity, the methods are up to date and admirably adapted to lay a sound foundation .. Should be very useful."-NATURE.

\section{ELEMENTARY ANALYSIS|}

by A. DAKIN, M.A., B.Sc., and R. I. PORTER, M.A.

Third Edition. Price 7 s.

"Teachers on the look-out for a good book covering the syllabuses of the Additional Mathematics for the School Certificate and of the Subsidiary Pure Mathematics for the Higher School Certificate will do well to inspect this volume. Very lucid and well arranged, and the numerous examples provide excellent practice for both average and more advanced pupils."-THE A.M.A.

\section{ELEMENTARY TREATISE ON PURE MATHEMATICS}

by N. R. CULMORE DOCKERAY, M.A. I7s. $6 d$. net.

Provides, in one comparatively inexpensive volume, a comprehensive course of elementary analysis suitable for scholarship candidates in schools and for University students.

"An admirable textbook undoubtedly a real contribution to school mathematics."-NATURE.

G. BELL \& SONS, LTD., PORTUGAL ST., W.C. 2 


\section{BE LL}

\section{GEOMETRY FOR SCHOOLS}

by A. H. G. PALMER, M.A., and H. E. PARR, M.A.

Fourth Edition. Price 5s. Also in two parts, 2s. 9d. each.

"There are several good points about this book. A great feature is made of easy riders, success in solving them will greatly encourage pupils. The bookwork is clearly set out, and is reduced to a minimum without neglect of essentials. And the examples are classified so that rapid selection can be made. An excellent course for the School Certificate."

THE A.M.A.

\section{A SCHOOL MECHANICS by C. V. DURELL, M.A.}

Tenth Edition. In three parts, $3 s .6 d$. each; parts I and II together, 6 s.

Parts I and II together cover the syllabus for the School Certificate, Part III contains the work required for the Higher School Certificate. "The bookwork and examples are admirable, and the whole book is very near the ideal introduction to mechanics."-JOURNAL OF EDUCATION.

\section{EXAMPLES IN MECHANICS}

by A. ROBSON, M.A., and C. J. A. TRIMBLE, M.A.

Second Edition, 4s. 6d. Hints, 5s. net.

"This book, intended for the use of those preparing for examinations of Higher Certificate or Scholarship standard, is by two men highly experienced and successful in this class of teaching, and should be extremely useful. . . All those teaching Mechanics to Mathematical Specialists are warmly advised to get this book."-MATHEMATICAL GAZETTE.

G. BELL \& SONS, LTD., PORTUGAL ST., W.C.2 